\title{
Thomas Jügel, Pollet Samvelian. “Topic agreement, experiencer constructions, and the weight of clitics"
}

Pegah Faghiri

\section{(2) OpenEdition}

Journals

Édition électronique

URL : https://journals.openedition.org/abstractairanica/53105

DOI : 10.4000/abstractairanica.53105

ISSN : 1961-960X

Éditeur :

CNRS (UMR 7528 Mondes iraniens et indiens), Éditions de l'IFRI

Référence électronique

Pegah Faghiri, «Thomas Jügel, Pollet Samvelian. "Topic agreement, experiencer constructions, and the weight of clitics" », Abstracta Iranica [En ligne], Volume 42-43 | 2021, document 8, mis en ligne le 30 décembre 2021, consulté le 19 décembre 2022. URL : http://journals.openedition.org/ abstractairanica/53105; DOI : https://doi.org/10.4000/abstractairanica.53105

Ce document a été généré automatiquement le 19 décembre 2022.

Tous droits réservés 
Thomas Jügel, Pollet Samvelian. "Topic agreement, experiencer constructions, and the weight of clitics"

Pegah Faghiri 


\section{RÉFÉRENCE}

Thomas Jügel, Pollet Samvelian. “Topic agreement, experiencer constructions, and the weight of clitics" in R. K. Larson, S. Moradi, V. Samiian (eds.). Advances in Iranian

Linguistics. Amsterdam: John Benjamins (Current Issues in Linguistic Theory 351), 2020, p. 137-153.

Cet article aborde la grammaticalisation des pronoms clitiques comme marqueurs d'accord dans les langues iraniennes pour corroborer le scénario selon lequel, lors du passage de l'alignement ergatif à l'accusatif, les clitiques coindexés avec le sujet (oblique) et correspondant au thème de la phrase, auraient été réanalysés comme marques d'accord sujet-verbe, remplaçant ainsi graduellement l'accord avec l'objet. Examinant la réalisation du sujet d'un point de vue historique, les auteurs soulignent les similarités entre les pronoms clitiques et les marques d'accord (c-à-d désinences verbale). En outre, ils reviennent sur les constructions du persan moderne, ex. sard=am ast 'j'ai froid', dans lesquelles l'expérienceur (réalisé ou non) est toujours coindexé avec un pronom clitique s'attachant à l'élément nominal du prédicat et le verbe restant à la troisième personne du singulier. En s'appuyant sur un ensemble d'exemples attestés, ils montrent que le groupe nominal qui réalise l'expérienceur présente les traits du sujet et, par conséquent, proposent d'analyser le clitique comme un marqueur d'accord. Cette construction illustrerait alors un cas de transition appuyant ainsi le scénario de la réanalyse.

\section{AUTEURS}

\section{PEGAH FAGHIRI}

University of Amsterdam 